\title{
IMPLEMENTASI BUSINESS INTELIGENCE MENENTUKAN DAERAH RAWAN GEMPA BUMI DI INDONESIA DENGAN FITUR GEOLOKASI
}

\author{
Ricky Akbar ${ }^{1}$, Ridho Darman ${ }^{2}$, Marizka $^{3}$, Jesi Namora ${ }^{4}$, Novisa Ardewati ${ }^{5}$ \\ $1,2,3,4,5$ Program Studi Sistem Informasi Fakultas Teknologi Informasi Universitas Andalas \\ 1,2,3,4,5 Jalan Universitas Andalas, Limau Manis, Pauh, Kota Padang, Sumatera Barat 25163 \\ ${ }^{1}$ rickyakbar1984@gmail.com ${ }^{2}$ ridhodarman@gmail.com
}

\begin{abstract}
Abstrak- Gempa bumi merupakan bencana alam yang dapat menimbulkan banyak kerusakan. Secara geografis, Indonesia terletak pada kawasan cincin api (ring of fire), yaitu lokasi yang sering mengalami bencana gempa bumi dan letusan gunung berapi. Badan Nasional Penanggulangan Bencana (BNPB) adalah Lembaga yang memiliki data tentang bencana yang terjadi di Indonesia dalam ukuran besar. Agar data tersebut dapat diolah menjadi informasi yang lebih bernilai, diperlukan aplikasi yang dapat memvisualisasikan data-data tersebut. Sehingga dapat menampilkan informasi berupa provinsi yang rawan bencana dan aman dari bencana khususnya gempa bumi. Penerapan business inteligence sangat cocok untuk kasus ini agar BNPB dapat mengelompokkan bencana khususnya gempa bumi di setiap provinsi yang ada di Indonesia untuk mempermudah masyarakat mendapat informasi bencana gempa bumi yang terjadi. Penelitian ini menggunakan salah satu aplikasi business inteligence yakni QlikView untuk dapat mengelompokkan bencana gempa bumi yang terjadi di setiap provinsi di Indonesia serta menampilkan visualisasinya pada peta menggunakan fitur geolokasi.
\end{abstract}

Kata kunci- Business Intelligence, Bencana, Gempa Bumi, QlikView, Geolokasi.

\section{Pendahuluan}

Bencana menurut Quarantelli (1998) dan diacu dalam Smith (2001) merupakan suatu kejadian aktual, lebih dari suatu ancaman yang potensial atau diistilahkan sebagai realisasi dari bahaya. [1] Bencana dapat mengancam semua wilayah di Indonesia baik di wilayah daratan maupun lautan. Badan Nasional Penanggulangan Bencana (BNPB) merupakan Lembaga Pemerintah Non-Departemen yang berfungsi untuk membantu Presiden Republik Indonesia dalam pengoordinasian pekerjaan penanggulangan bencana serta perumusan dan penetapan garis haluan penanggulangan bencana dan penanganan pengungsi dengan bereaksi secara cepat dan tepat, efektif dan efisien. Badan ini mempunyai data bencana, baik bencana alam maupun non-alam yang terjadi di Indonesia. [2]

Indonesia merupakan kawasan yang sering mengalami kejadian bencana alam berupa gempa bumi karena terletak di pertemuan tiga lempeng tektonik besar, yaitu Lempeng Pasifik, Indo-Australia, dan Eurasia. [3] Banyaknya data bencana khususnya gempa bumi yang terdapat pada BNPB harus terorganisir dan sistematis sehingga mempermudah dalam pengambilan keputusan. Misalnya pengelompokkan bencana gempa bumi pada tiap provinsi serta kedalamannya di seluruh Indonesia. Pengelompokkan bertujuan agar masyarakat dan BNPB khususnya dapat mengetahui provinsi mana saja yang rawan bencana dan provinsi yang aman dari bencana khususnya gempa bumi sebagai acuan bagi Kementerian PUPR (Pekerjaan Umum dan Perumahan Rakyat) dalam perumusan dan penetapan dalam penyelenggaraan jalan, pengembangan kawasan dan penyediaan perumahan pemukiman sesuai dengan Peraturan Menteri PUPR Nomor 15/PRT/M/2015. Penerapan business intelligence merupakan salah satu solusi terbaik untuk mengatasinya. Business intelligence meliputi informasi dan perolehan data dari berbagai sumber dan mengolahnya untuk keperluan pengambilan keputusan.

Pada penelitian ini, digunakan sebuah aplikasi business intelligence untuk membantu BNPB dalam mengkoordinir data yang dimilikinya. QlikView adalah salah satu aplikasi business intelligence yang digunakan pada penelitiaan ini untuk dapat mengelompokkan provinsi di Indonesia termasuk provinsi yang aman bencana atau rawan bencana berdasarkan data yang diperoleh dari BNPB khususnya gempa bumi. QlikView juga memiliki ekstensi OpenStreetMap yang memudahkan visualisasi data ke dalam peta dengan memanfaatkan fitur geolokasi yang bisa digunakan pada OpenStreetMap. Fitur geolokasi yang ditampilkan berupa titik-titik koordinat lokasi berdasarkan data latitude dan longitude gempa bumi tersebut.

\section{STUDI LiterATUR}

\section{A. Business Intelligence}


Menurut Howard Dresner, business intelligence merupakan seperangkat metode dan konsep yang berfungsi untuk meningkatkan kemampuan membuat keputusan dengan bantuan sistem yang berlandaskan pada fakta-fakta yang terjadi. [4]

Arsitektur Business Intelligence memiliki empat komponen:

1. Data warehouse, yang merupakan sumber data tersimpan yang terdiri dari historis data yang sudah diorganisasikan.

2. Business analytic, sekumpulan tools yang untuk menganalisa, mining, dan memanipulasi data pada warehouse.

3. Business Performance Management (BPM), difungsikan untuk menganalisis dan memantau kinerja.

4. User Inteface (Dashboard), menyediakan informasi berupa tampilan grafis pengukuran performa perusahaan. [5]

Konsep business intelligence mengutamakan penerapan informasi untuk kebutuhan spesifik bisnis, sebagai berikut:

1. Data Sourcing

Berhubungan dengan penguasaan sistem untuk mengakses data dan informasi yang bervariasi dari sejumlah sumber dengan format yang berbeda.

2. Data Analysis

Berhubungan dengan penguasaan sistem dalam proses penciptaan pengetahuan melalui aktivitas menganalisis informasi dan data yang dimiliki perusahaan.

3. Situation Awareness

Berhubungan dengan penguasaan sistem untuk mencari dan menyediakan informasi dan data mengenai kebutuhan bisnis pada saat tertentu.

4. Risk Analysis

Berhubungan dengan penguasaan sistem untuk melakukan penghitungan ratio yang akan dihadapi perusahaan terhadap kemungkinan atau kecenderungan yang dapat terjadi.

5. Decission Support

Berhubungan dengan penguasaan sistem yang aktif mendukung manajemen dalam mempertimbangkan sejumlah keputusan berdasarkan kalkulasi dan pengolahan terhadap data atau informasi internal ataupun eksternal yang dimiliki. [6]

Beberapa manfaat yang diperoleh oleh suatu organisasi atau perusahaan saat mengimplementasikan business intelligence, yakni:

1. Meningkatkan nilai informasi dan data organisasi. Melalui pembangunan business intelligence, seluruh informasi dan data dapat diintegrasikan sehingga dapat membentuk pengambilan keputusan.

2. Memudahkan pengamatan kinerja organisasi. Pada penghitungan kinerja dalam suatu organisasi, sering digunakan ukuran yang disebut dengan Key Performance Indicator (KPI). Dengan demikian, pihak-pihak yang terlibat dalam pengambilan keputusan akan lebih efisien dalam melakukan langkah-langkah antisipasi.

3. Meningkatkan nilai investasi teknologi informasi yang sudah ada. Business intelligence tidak selalu harus merombak atau menukar sistem informasi yang pernah digunakan sebelumnya. Sebaliknya, business intelligence hanya menambahkan layanan sistem sehingga data dan informasi yang ada bisa menciptakan informasi yang lebih menyeluruh.

4. Menjadikan pegawai memiliki akses informasi yang baik (well-informed workers). Business intelligence mempermudah seluruh tingkatan pegawai ketika mengakses data dan informasi.

5. Meningkatkan efisiensi biaya. Melalui business intelligence dapat menambah efisiensi karena mempermudah pekerjaan, mempersingkat waktu, dan mudah dalam pemanfaatannya. [7]

\section{B. Bencana Alam}

Merujuk pada UU No. 24 Tahun 2007 Tentang Penanggulangan Bencana pada bab 1 pasal 1, definisi dari bencana alam ialah bencana yang dihasilkan oleh serangkaian peristiwa atau peristiwa yang dikarenakan oleh alam diantaranya berupa tsunami, gempa bumi, kekeringan, banjir, angin topan, gunung meletus, dan tanah longsor. [8]

Gempa bumi merupakan bencana alam yang timbul dari dampak pelepasan energi dari dalam bumi secara tiba-tiba, ditandai dengan adanya patahan pada lapisan batuan di kerak bumi. Pengumpulan energi pemicu terjadinya gempa bumi tersebut berasal dari pergerakan lempeng-lempeng tektonik. Energi yang diperoleh dekeluarkan kesegala arah dalam bentuk gelombang gempa bumi sehingga dampaknya bisa dirasakan sampai ke permukaan bumi. [9]

Gempa bumi dibagi menjadi 3 golongan berdasarkan kedalamannya:

1. Gempa bumi dalam

Hiposentrum gempa bumi dalam berada lebih dari $300 \mathrm{~km}$ di bawah permukaan bumi (terjadi di dalam kerak bumi). Gempa bumi ini biasanya tidak terlalu membahayakan.

2. Gempa bumi menengah

Hiposentrum gempa bumi menengah berada diantara $60 \mathrm{~km}$ hingga $300 \mathrm{~km}$ di bawah permukaan bumi. Getaran yang diakibatkan gempa 
bumi golongan ini lebih terasa dibandingkan gempa bumi dalam dan dapat mengakibatkan kerusakan ringan.

3. Gempa bumi dangkal

Hiposentrum dari gempa bumi dangkal kurang dari $60 \mathrm{~km}$ dari permukaan bumi. Gempa bumi ini pada umumnya menyebabkan kerusakan besar. [10]

Indonesia dan sekitarnya adalah daerah yang paling aktif seismiknya di bumi. Di bagian selatan, terdapat sabuk gunung api Sunda yang memanjang $3.000 \mathrm{~km}$ dari timur ke barat, yang merupakan hasil dari subduksi Lempeng Australia dengan Lempeng Eurasia di utara. Pada sabuk vulkanik di timur laut Sulawesi, lempenglempeng kecil membentang dari arah selatan ke utara dan menunjukkan kegiatan yang kompleks dan dinamis. Dalam bagian barat dari Java Trench (atau Sunda Parit), plate bergerak sebesar $6 \mathrm{~cm}$ per tahun di mana $5 \mathrm{~cm}$ nya di bagian timur. Pada beberapa tahun tertentu, di dekat Pulau Papua terjadi pergerakan lempeng sebesar $10 \mathrm{~cm}$. Di Indonesia terdapat banyak gunung api aktif dan tidak aktif yang membentuk ring of fire, oleh sebab itu seringkali terjadi bencana gempa bumi yang juga diakibatkan letusan gunung berapi. [11]

\section{QlikView}

QlikView merupakan software bussiness inteligence yang didirikan oleh perusahaan QlikTech. QlikView juga mendukung geoanalityc yang dapat menampilkan informasi penting berupa informasi geospasial dan mengekspos hubungan geografis tersembunyi untuk membuat keputusan terkait lokasi yang lebih baik. Visualisasi dan analisis geospasial pada QlikView tidak hanya menyediakan kemampuan pemetaan yang komprehensif, tetapi juga bergerak diluar visualisasi dengan dukungan built-in untuk berbagai kasus penggunaan geoanalityc yang canggih untuk menampilkan informasi geospasial. [12] Fitur untuk menampilkan informasi geospasial pada QlikView dapat digunakan dengan memanfaatkan ekstensi OpenStreetMap yang terdapat pada QlikView. OpenStreetMap adalah proyek pembuatan peta yang dibangun oleh komunitas pembuat peta yang berkontribusi dan memelihara data tentang jalan, jalur, kafe, stasiun kereta api, dan lainnya, di seluruh dunia. OpenStreetMap menekankan pengetahuan lokal. Kontributor menggunakan citra udara, perangkat GPS, dan peta lapangan berteknologi rendah untuk memverifikasi bahwa OSM akurat dan termutakhir. OpenStreetMap menggunakan data terbuka, berlisensi di bawah Open Data Commons Open Database License (ODbL) oleh OpenStreetMap Foundation (OSMF). [13]

\section{Metodologi}

Metode penelitian yang dilakukan untuk menganalisis penentuan daerah rawan bencana gempa bumi menggunakan 2 metode:

1. Metode melalui studi literatur.

2. Metode eksperimen dengan menggunakan beberapa tahapan diantaranya:
a. Pengumpulan data.
b. Cleaning Data.
c. Implementasi pada QlikView
d. Analisis hasil.

Skema tahapan penelitian ditunjukkan pada Gbr. 1.

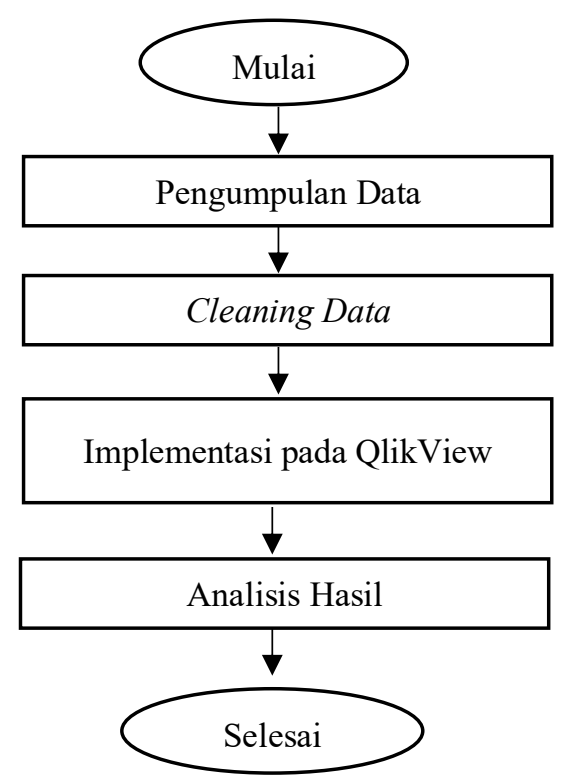

Gbr. 1 Tahapan Penelitian

\section{PEMBAHASAN DAN HASIL}

Pada bab ini akan diuraikan mengenai hasil penelitian serta pembahasan dari hasil penelitian "Implementasi Business Intelligence Menentukan Daerah Rawan Gempa Bumi di Indonesia Dengan Fitur Geolokasi". Pembahasan ini berisi bagaimana hasil dari pengolahan data-data bencana gempa bumi yang ada sehingga nanti didapati output berupa grafik tentang daerah yang termasuk rawan terhadap bencana gempa bumi serta daerah yang aman dari bencana gempa bumi dari seluruh provinsi di Indonesia.

\section{A. Pengumpulan Data}

Data yang didapatkan berasal dari BNPB. Data tersebut merupakan data tentang bencana gempa bumi yang diambil di seluruh Indonesia. Data bencana gempa bumi yang diperoleh sebanyak 975 kejadian. Data yang diperoleh dalam bentuk format excel, 
kemudian disesuaikan agar dapat di import ke database dan dianalisa menggunakan QilkView.

\section{B. Cleaning Data}

Cleaning Data adalah suatu proses mendeteksi dan memperbaiki (atau menghapus) data set, tabel, dan database yang corrupt atau tidak akurat. Istilah ini mengacu pada identifikasi data tidak lengkap, tidak benar, tidak tepat, dan tidak relevan, kemudian dirty data tersebut akan diganti, dimodifikasi atau dihapus. Proses cleaning data ini cukup penting dalam pembangunan data warehouse untuk mencegah terjadinya duplikat data, ambigu pada data dan konflik penamaan. [14]

\section{Implementasi pada QilkView}

Setelah proses import data berhasil dilakukan, kemudian lakukan pengolahan data pada QlikView. Langkah-langkah yang dilakukan untuk mengolah data pada QilkView sebagai berikut:

1. Membuat jendela baru pada QlikView.

2. Import data menggunakan script editor. Hal ini dilakukan agar data latitude dan longtitude bisa di load sebagai geolokasi menggunakan fitur GeoMakePoint pada QlikView.

3. Memilih jenis grafik yang akan dibuat dengan membandingkan antara dimension dan measure.

4. Measure yang digunakan merupakan nilai yang akan kita bandingkan seperti jumlah, rata-rata, nilai maksimum maupun nilai minimum dari suatu data.

5. Tahapan terakhir adalah membuat sebuah dashboard.

Pada dashboard gempa bumi akan ditampilkan jumlah kejadian gempa bumi tahun 2010-2014, jenis gempa bumi berdasrkan kedalaman dan lokasi kejadian gempa bumi pada peta. Dashboard seluruh bencana gempa bumi Indonesia dapat dilihat pada Gbr. 2.

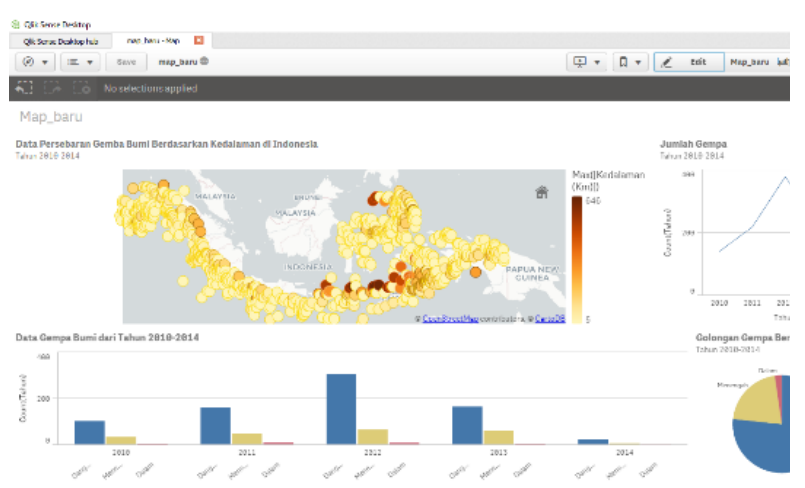

Gbr. 2 Tampilan Dashboard Bencana Gempa Bumi
Grafik jumlah kejadian bencana gempa bumi yang terjadi dari tahun 2010-2014 di Indonesia dapat dilihat pada Gbr. 3.

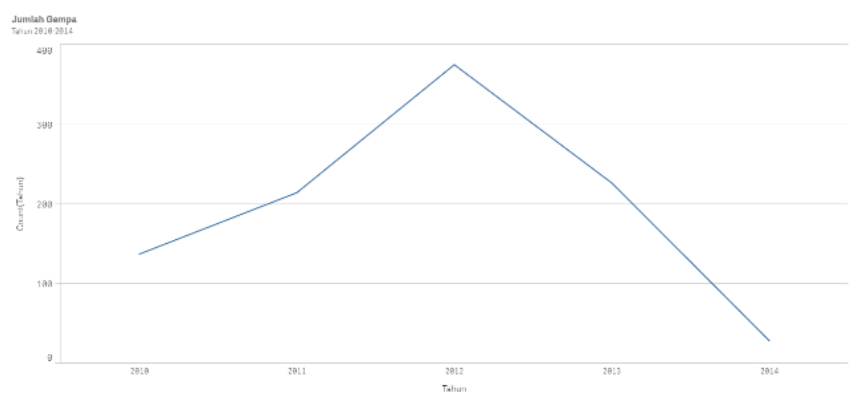

Gbr. 3. Grafik Jumlah Gempa Bumi yang Terjadi Dari Tahun 20102014 di Indonesia

Pada Gbr 3 dapat dilihat jumlah kejadian bencana gempa bumi di Indonesia cenderung mengalami fluktuasi. Jumlah bencana gempa bumi terbanyak terjadi pada tahun 2012. Frekuensi bencana gempa bumi yang terjadi tahun 2010-2012 terus mengalami peningkatan, sedangkan tahun 2012-2014 mengalami penurunan. Kemudian peta data persebaran bencana gempa bumi berdasarkan kedalaman dari tahun 20102014 di Indonesia dapat dilihat pada Gbr. 4.

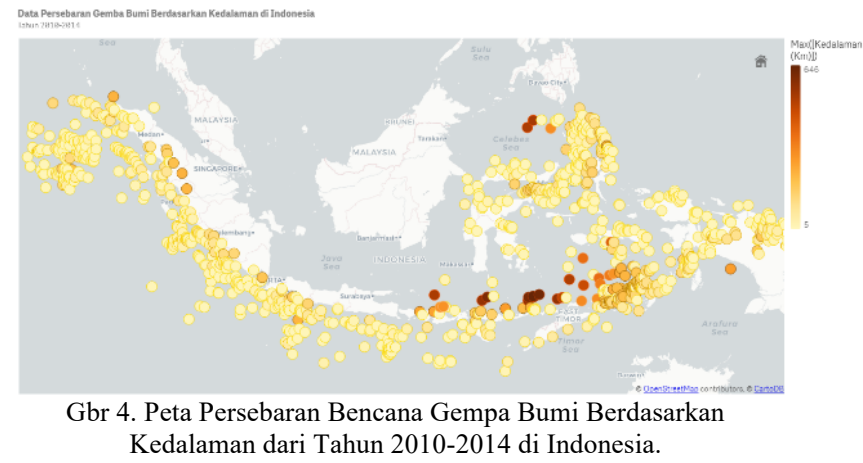

Pada Gbr. 4 ditampilkan titik persebaran bencana gempa bumi menggunakan fitur geolokasi, titik persebaran tersebut ditampilkan dengan memanfaatkan ekstensi OpenStreetMap yang tersedia pada QlikView. Titik persebaran bencana gempa bumi didapat dari koordinat berupa latitude dan longitude. Pada peta tersebut titik bencana gempa bumi ditampilkan berdasarkan lokasi bencana gempa bumi dan kedalamannya, semakin gelap warna titik gempa menunjukkan semakin tinggi tingkat kedalaman gempa bumi. Pada peta persebaran bencana gempa bumi dapat diketahui bahwa pulau Kalimantan adalah daerah yang paling aman dari gempa bumi karena tidak terdapat titik kejadian gempa bumi, sedangkan daerah yang rawan gempa adalah tepi barat pantai Sumatera, selatan Pulau Jawa, Maluku, Kepulauan Nusa Tenggara dan utara Pulau Papua. Titik kejadian gempa bumi yang terjadi 
tahun 2010-2014 didominasi oleh warna terang menunjukkan gempa bumi yang terjadi kebanyakan bergolongan gempa bumi dangkal. Gempa bumi dikelompokkan berdasarkan kedalamannya ditampilkan pada Gbr. 5 .

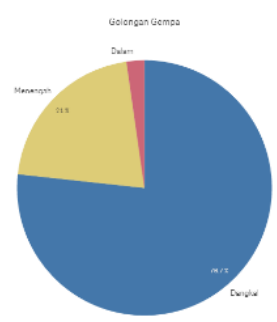

Gbr. 5. Golongan Gempa Bumi Berdasarkan Kedalaman

Pada Gbr 5 dapat dilihat mayoritas golongan gempa yang terjadi pada tahun 2010-2014 adalah gempa bumi dangkal yaitu sebanyak $76.7 \%$ dari 975 kejadian. Sedangkan gempa bumi golongan menengah hanya $21 \%$, dan yang paling sedikit yaitu gempa bumi dalam sebanyak 2,3\%. Jumlah gempa bumi berdasarkan kedalamannya yang terjadi pada tahun 2010-2014 dapat dilihat pada Gbr. 6 .

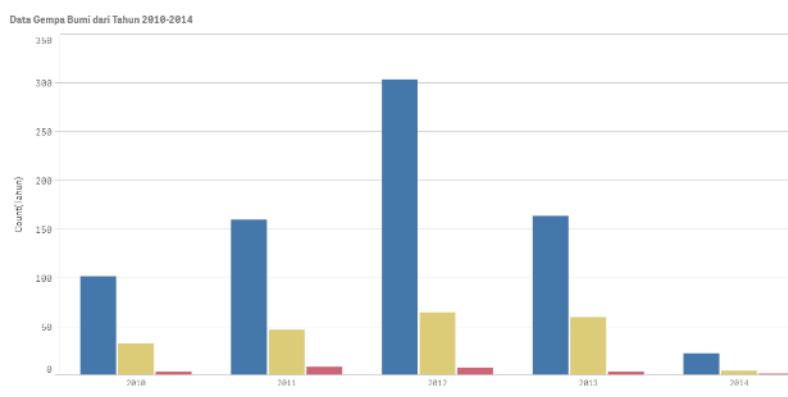

Gbr. 6. Data Bencana Gempa Bumi Berdasarkan Kedalaman dari Tahun 2010-2014

Pada Gbr 6 ditampilkan jumlah bencana gempa bumi yang terjadi berdasarkan kedalaman dari tahun 2010-2014 dimana setiap tahunnya bencana gempa bumi yang terjadi pada tahun 2010-2014 mayoritas termasuk golongan gempa bumi dangkal dan yang paling sedikit tiap tahunnya ialah gempa bumi dalam. Kemudian ditampilkan lima daerah yang paling rawan gempa bumi dari tahun 2010-2014 seperti pada Gbr 7.

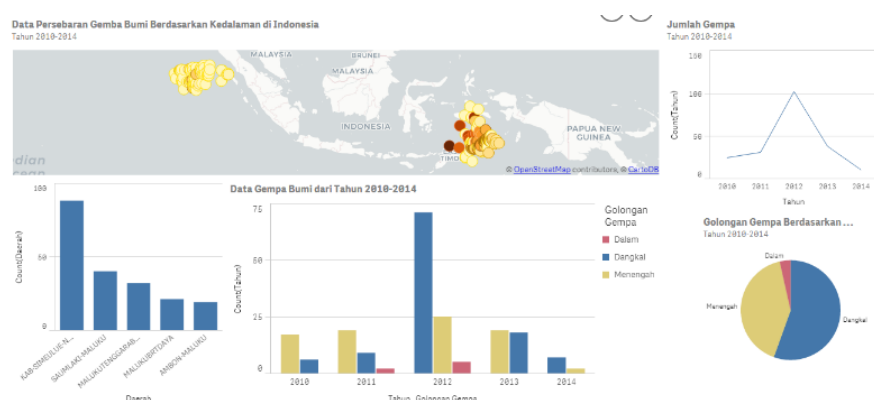

Gbr. 7. Data Lima Daerah Rawan Gempa Bumi dari Tahun 20102014

Pada Gbr. 7 dapat dilihat bahwa daerah yang paling rawan gempa bumi adalah Kabupaten Simeulue, Provinsi Nanggroe Aceh Darussalam dan pada posisi kedua, ketiga, keempat, dan kelima ditempati oleh daerah Saumlaki, Maluku Tenggara Barat, Maluku Barat Daya, dan Ambon. Pada tahun 2010, 2011, dan 2013 lima daerah rawan gempa bumi didominasi oleh gempa bumi dengan kedalaman menengah. Sedangkan pada tahun 2012 dan 2014 didominasi oleh gempa bumi dengan kedalaman dangkal. Gempa bumi yang terjadi pada lima daerah rawan gempa bumi kebanyakan terjadi pada tahun 2012 .

\section{Analisis Hasil}

Pada penelitian ini digunakan QlikView sebagai aplikasi business intelligence dalam memperoleh informasi baik berupa grafik maupun data-data yang diperlukan dapat di analisis bahwa daerah yang paling rawan terjadinya bencana gempa bumi di Indonesia adalah daerah tepi barat pantai Sumatera, selatan Pulau Jawa, Kepulauan Nusa Tenggara, Maluku Utara dan utara Pulau Papua. Sedangkan Pulau Kalimantan adalah daerah yang tidak termasuk rawan terjadinya bencana gempa bumi. Pada bagian sebelumnya telah dipaparkan grafik jumlah gempa bumi dari tahun 20102014 di Indonesia menghasilkan kesimpulan bahwa gempa bumi sering terjadi pada tahun 2012 dengan jumlah gempa yang terjadi lebih dari 300 kali. Gempa yang terjadi pada tahun 2012 kebanyakan adalah golongan gempa dangkal. Kabupaten Simeulue, Provinsi Nanggroe Aceh Darussalam adalah daerah yang paling rawan terhadap gempa bumi. Pada lima daerah yang paling rawan terhadap gempa bumi, jumlah gempa dangkal, menengah, dan dalam selalu mengalami peningkatan frekuensi kejadian gempa bumi dari tahun 2010-2012, sedangkan pada tahun 2012-2014 mengalami penurunan.

\section{KESIMPULAN}

Indonesia merupakan negara yang rawan mengalami bencana gempa bumi. Pada umumnya bencana gempa bumi yang terjadi di Indonesia adalah gempa bumi dangkal yang mengakibatkan banyak kerusakan. 
Berdasarkan data bencana gempa bumi yang terjadi dari tahun 2010-2014 di Indonesia dengan menggunakan bantuan aplikasi QlikView, maka hasil yang dapat disimpulkan:

1. Daerah tepi barat pantai Sumatera, selatan Pulau Jawa, Maluku Utara, Kepulauan Nusa Tenggara dan utara Pulau Papua merupakan daerah paling rawan gempa bumi pada tahun 2010 - 2014.

2. Pulau Kalimantan merupakan daerah yang paling aman gempa bumi sepanjang tahun 2010-2014.

3. Dari tahun 2010-2012 frekuensi gempa bumi terus meningkat, sedangkan dari tahun 2012-2014 frekuensi gempa bumi terus menurun.

4. Gempa bumi paling banyak terjadi pada tahun 2012, dengan frekuensi lebih dari 300 kali.

5. Gempa bumi dangkal merupakan gempa bumi yang paling sering terjadi pada tahun 2010-2014

6. Frekuensi terjadinya gempa bumi dangkal dan menengah mengalami peningkatan pada tahun 2010-2012, sedangkan pada tahun 2012-2014 mengalami penurunan.

7. Kabupaten Simeulue, Provinsi Nanggroe Aceh Darussalam merupakan daerah yang paling rawan gempa bumi.

QlikView sangat membantu untuk menampilkan informasi daerah yang rawan gempa bumi, daerah yang aman dari kejadian gempa bumi dan jenis gempa bumi yang terjadi berdasarkan kedalamannya sehingga user atau pengguna, terutama masyarakat Indonesia bisa mengetahui lokasi yang rawan bencana gempa bumi dan merancang mitigasi resiko terhadap gempa bumi di setiap daerah untuk meminimalisir korban jiwa, merancang struktur bangunan tahan gempa untuk mengindari kerusakan dan sebagainya, terutama untuk daerah-daerah yang memiliki riwayat rawan gempa bumi. Hal ini juga bisa menjadi pertimbangan dalam pengambilan keputusan oleh Pemerintah Indonesia dalam hal ini Kementerian PU PR dalam menetapkan kebijakan standar pendirian bangunan gedung dan perumahan sesuai dengan kondisi alam daerah di Indonesia, serta membantu BNPB dalam upaya mengkoordinasikan dan meningkatkan kesiapsiagaan mitigasi bencana alam khususnya pada daerah yang rawan terjadinya bencana gempa bumi.

\section{REFERENSI}

[1] M. Mubekti, "Mitigasi Daerah Rawan Tanah Longsor Menggunakan Teknik Pemodelan Sistem Informasi Geografis; Studi Kasus: Kecamatan Sumedang Utara dan Sumedang Selatan," Jurnal Teknologi Lingkungan, vol. 9, no. 2, pp. 121-129, 2011.

[2] R. Akbar, "Analisis Hasil Implementasi Business Intelligence Menentukan Daerah Rawan Banjir dan Kebakaran di Indonesia," Jurnal Edukasi dan Penelitian Informatika, vol. 3, no. 1, pp. 65-70., 2017.
[3] G. A. T. Pasau, "Pemodelan Sumber Gempa di Wilayah Sulawesi Utara Sebagai Upaya Mitigasi Bencana Gempa Bumi," Jurnal Ilmiah Sains, vol. 11, no. 2, pp. 202-209, 2011.

[4] D. Pareek, Business Intelligence for telecommunications, CRC Press, 2006.

[5] G. Prajena, V. Yesmaya, D. Darmawan dan H. Sudarma, "Arsitektur Business Intelligence Berorientasi User," Jurnal Teknik dan Ilmu Komputer, vol. 03, no. 10, pp. 157-163, 2014.

[6] E. Miranda, "Pengembangan Business Intelligence Bagi Perkembangan Bisnis Perusahaan," CommIT (Communication and Information Technology), vol. 2, no. 2, pp. 111-116, 2008.

[7] S. W. S. S. W. Suparto Darudiato, "Business Intelligence : Konsep dan Metode," Communication and Information Technology Journal, pp. 63-67, 2016.

[8] Undang-Undang Republik Indonesia Nomor 24 Tahun 2007 Tentang Penanggulangan Bencana.

[9] Badan Meteorologi Klimatologi dan Geofisika, "Indonesia Tsunami Early Warning System,” 2016. [Online]. Available: https://inatews.bmkg.go.id/new/tentang_eq.php.

[10] H. Murtianto, "Potensi Kerusakan Gempa Bumi Akibat Pegerakan Patahan Sumatera Di Sumatera Barat Dan Sekitarnya," Jurnal Geografi Gea, vol. 10, no. 1, p. 4, 2010.

[11] Mitsui Sumitomo Insurance Group Interisk Asia PTE LTD, "Earthquake Risk in Indonesia," Asian Risk Information Journal Interisk Asia, p. 2, 2009.

[12] QlikTech International AB, "Mapping and Location-Based Analytics," 2018. [Online]. Available: https://www.qlik.com/us/products/qlik-geoanalytics. [Diakses 2142018 ].

[13] OpenStreetMap, “OpenStreetMap,” [Online]. Available: https://www.openstreetmap.org/about. [Diakses 214 2018].

[14] A. Riezka, Analisis dan Implementasi Data-Cleaning dengan Menggunakan Metode Multi-Pass Neighborhood (MPN), 2011 . 